\title{
Chapter 5 \\ Conditioning Principles: On Bioethics and the Problem of Ableism
}

\author{
Joel Michael Reynolds
}

What it is to be human is not a bundle of capacities. It's a way that you are, a way you are in the world, a way you are with another.

Eva Kittay (2009, 622).

There is a large literature examining the relationship between principles and biomedicine, much of which operates on the assumption that principles are theoretically and practically fruitful. That is to say, principles are considered a useful tool for normative theorizing, and due to that use, they assist guiding practitioners in the equitable delivery of healthcare. This paper contributes to that literature by exploring an underappreciated way in which principles can instead actively undermine normative theorizing in general and the delivery of equitable healthcare in particular. As a case study to understand this problem, I show how ableism is one such principle, demonstrate its negative impact on achieving aims of justice as fairness in medicine, and suggest some ways forward.

I proceed by assuming two types of audiences: one that will be more interested in the take-aways of this analysis for concrete bioethical inquiry (i.e., take-aways that have purchase for clinical bioethicists, hospital review boards, and related domains) and another that will be more interested in the philosophical steps that underwrite the argument (namely, philosophy or other humanities professors who do research in bioethics and who may or may not be especially concerned about application). Section 5.2 is solely for the latter audience, so bioethicists whose interests are driven by the constraints of real-world healthcare delivery can safely skip it. The rest of the sections, I hope, will be of interest to both camps.

\footnotetext{
J. M. Reynolds ( $\triangle)$

Department of Philosophy and Kennedy Institute of Ethics, Georgetown University,

Washington, DC, USA

e-mail: joel.reynolds@georgetown.edu
}

E. Victor, L. K. Guidry-Grimes (eds.), Applying Nonideal Theory to Bioethics, Philosophy and Medicine 139, https://doi.org/10.1007/978-3-030-72503-7_5 
In Sect. 5.1, I briefly rehearse bioethics' much-discussed relationship with principlism, which is to say, its longstanding methodological reliance upon the application of general principles to particular, individual cases as part of its defining institutional service to the practice of biomedicine. In Sect. 5.2, I explain what I mean by a "principle". I then show how ableism functions both in bioethical theory and biomedical practice as a conditioning principle: a principle that implicitly or explicitly grounds, limits, or otherwise determines the construction and role of other principles. In Sect. 5.3, I show ableism at work in this way through an analysis of the famous debate between Eva Kittay, Peter Singer, and Jeff McMahan. In short, ableism structures how we think about the meaning of being human and the relationship between humans and wellbeing, and it operates implicitly-silently or stealthily - in ways that condition or place parameters upon the possibility of other principles or guidelines for thought and action. In Sects. 5.4 and 5.5, I argue that one of the primary ways conditioning principles such as ableism maintain and further unjust practices, and thereby actively undercut the ideals and praxis of justice, is through epistemologies of ignorance, which are fomented by ideal theory approaches. It is for this reason, I contend, that conditioning principles should be a focus of those committed to nonideal theory.

A proviso is in order. First, although I speak at length of principles and their import, I neither delve into the large literature on the role of principlism in bioethics-whether in general (see, e.g., Clouser and Gert 1990) or with respect to particular principles (Francis 2017)—nor do I delve into related questions of methodology for bioethical inquiry (Jonsen et al. 1988). I do not substantively engage this literature because I will not argue for or against the role of principles for bioethical inquiry or biomedical practice. I instead argue that conditioning principles play a significant role in bioethical inquiry and in biomedical practice that has been largely underexamined, that this role can undermine the normative aims of bioethical and biomedical thinking and practice, and that this role should thus be subjected to critical scrutiny.

\subsection{Medicine, Bioethics, and Justice}

Whichever side one takes concerning debates in the philosophy of medicine over the internal morality of medicine, most agree that medicine is practiced best when oriented by the end of helping patients (Symons 2019; Ben-Moshe 2017)). Thus, whether or not the intrinsic goal of medicine is in fact to help patients, it should be. In turn, the goal of bioethics, at least with regard to its origins, is to help guide practitioners through the articulation of, reflection upon, and implementation of ethically grounded practices that will bring about its guiding goal (cf. Arras 2001). ${ }^{1}$

\footnotetext{
${ }^{1}$ Put less diplomatically, bioethics arose to counterbalance the many egregiously unethical and unjust practices and actions carried out under the banner of "medicine" and "scientific progress" across the globe (Washington 2008).
} 
Famously, though to some notoriously, one way in which the field of bioethics initially carried out this goal was via the positing or, depending upon how one sees it, articulation of principles. Canonized by Beauchamp and Childress, bioethics' four primary principles-respect for autonomy, beneficence, nonmaleficence, and justice-were conceived as "general norms that leave considerable room for judgment in many cases" (Beauchamp and Childress 2001, 13). Beauchamp and Childress assume that from principles flow rules that will guide judgments leading toward morally defensible action. It bears repeating, however, that these principles, dubbed the "Georgetown mantra," were not intended to function as "precise action guides that inform us in each circumstance how to act in the way that more detailed rules and judgments do." 2

Furthermore, and with the notable exception of the principle of justice, the Georgetown mantra was conceived with the care of individual clinical and research patients in mind. These core three principles, then, were not understood as or intended to be principles of public health, for example. This is understandable and, in many ways, expected, since historically the object of medical care has been the individual patient.

Put roughly, then, the role of bioethics from its origins in the 1960s and 1970s, to its many transformations and expansions in the late $80 \mathrm{~s}$ and $90 \mathrm{~s}$, and on to the increasingly institutionalized and manifold forms it takes today has, by and large, been shaped by a historical focus on norms pertaining to individualized care (Evans 2012; Wilson 2013). The rise of fields such as public health and social epidemiology in some ways reinforced bioethics' focus to the point that many simply take this for granted as bioethics' characteristic function amidst the larger panoply of medical practices, institutions, fields, and services, whether primarily academic or otherwise in nature.

This leads us back to the unique role of principles in relation to bioethics and biomedical practice. When principlism came under growing criticism in the late $80 \mathrm{~s}$ and early 90s, this focus on the individual maintained its grip across bioethics as a whole and did so for expected sociological reasons (see Evans 2000). ${ }^{3}$ Take the concepts of 'autonomy,' 'dignity,' 'respect,' and 'choice': each of these, albeit in their own way, undergirded and animated all four of bioethics' canonical principles. This is all to say, one of the legacies of principlism in bioethics is the assumption that whatever form bioethics takes and whatever methods it employs-whether principlism, casuistry, contextualism, naturalism, empirical bioethics, feminist

\footnotetext{
${ }^{2}$ Of course, Beauchamp and Childress were drawing and expanding upon the three principles of respect for persons, beneficence, and justice as first laid out in the Belmont report.

${ }^{3}$ To be clear, I am sketching a picture that focuses on dominant themes in the literature. The full story is, of course, far more complex and involves the multiple, sometimes conflicting timelines and histories of "bioethics" as the field increasingly expands-and, there is an argument to be made, significantly fractures - from the early 90s onward.
} 
approaches, etc.-bioethics best serves medicine by focusing its reflective and practical efforts on the care of individuals. ${ }^{4}$

Yet, as multiple commentators have argued, this historical and exclusive focus on the care of the individual is in tension with feminist critiques concerning the principle of justice, both with respect to its meaning and application. For example, scholars like Eva Feder Kitty and Martha Fineman argue that insofar as we are all inevitably dependent, we are all inextricably interdependent (Kittay 1999; Fineman 2004). To understand the ends of medicine as focused on the individual is to misconstrue the nature of caring systems. Caring systems, in order to actually deliver care, must be focused on the relations and complex structures in and through which any given individual is afforded the conditions of a well-cared-for life. A sole focus on the individual simply misunderstands what it means to care. ${ }^{5}$

Supporting this concern over an idealized, individualistic focus, there is a large and growing body of evidence demonstrating that interventions focused at the level of an individual's body will in many respects be a poor substitute for interventions focused at larger interactions with an individual's environment (Morar and Skorburg 2018; Ariga and Heiman 2018). Economic stability, reliable access to healthy foods, high-quality and continuing education, a clean environment, safe and supportive forms of labor, caring and durable systems of interpersonal support: these are the primary determinates of health. It is hard to overstate the import of the fact that one's zip code is a better predictor of health than one's genomic code. Seen in the light of such evidence, the oaths of Hippocrates and Maimonides, focused as they are on the individual patient, seem today quaint in both scope and aim, if not sorely misguided.

But what if the problem of this historical focus on the individual patient goes deeper? What if the principles built upon and out of this focus reveal an even deeper theoretical committment, namely, the commitment to the principle that abilities are properties, characteristics, or features of individuals?

\footnotetext{
${ }^{4}$ As Alica Oulette writes, "despite its many faces, bioethics has as its core a central concern with respect for persons through respect for individual autonomy and good medical care." (Ouellette 2011, 30). My thanks to Joe Stramondo's article, "Disabling bioethics: The case for a disability moral psychology and epistemology" for bringing my attention to this quote (Stramondo 2014; cf. Stramondo 2016).

${ }^{5}$ To be clear, this critique is less apropos for the field of public health, which often takes the principle of justice and the necessity and nature of caring systems more seriously. Though whether and how it does so in theory as opposed to in practice is a more complicated question. Leslie P. Francis notes that "justice has tended to come last" in the "teaching and practice not only of bioethics but of other fields in applied ethics." Among other reasons, this is because "justice isn't a single principle, but a topic area in social, political, and moral philosophy. There is deep disagreement about which principle(s) of justice to adopt, and why" (Francis 2017, 1). The critique of the historical focus of bioethical inquiry on the individual turns on both the scope and application of normative arguments in this domain. Put bluntly, a large swath of bioethical inquiry especially that which occurs inside or in close relation to the field of philosophy, eschews questions of justice in order to focus on narrower concerns. Paradigmatic questions include, for example, "what is an MD in specialist field $\mathrm{X}$ to do in situation $\mathrm{Y}$ under constraints $\mathrm{W}$ and $\mathrm{Z}$ given normative theories $\mathrm{A}, \mathrm{B}$, or $\mathrm{C}$ ?"
} 


\subsection{Principles, Epistemic Schemas, and Normative Force}

Before I can defend such a claim, I must define my terms. For the purposes at hand, I define a principle as (i) a proposition or set of propositions taken to be true for all phenomena to which it refers or otherwise generalizes over, (ii) which acts as the basis or foundation for further reasoning, judgment, belief, or related cognitive processes, and (iii) which can function prereflectively or reflectively. Principles are generalizations involving sufficient content to guide action across a wide set of circumstances. They act as a foundation for further cognition in the sense that they can help produce a wide range of action-guiding inferences. Principles, as should be obvious, are not concepts: they do not group or gather particular things under an overarching category or notion. By definition, principles don't have particulars under them.

Principles have many varied functions and effects, and they thus come in many varieties. Although on this definition, principles are construed as matters of thinking or cognition, they have material consequences and can profoundly shape and direct habits, comportment, and praxis at the individual level as well as larger social patterns, practices, and institutions.

Principles have this wide-ranging effect through two primary mechanisms: the creation of (a) epistemic schemas in particular and (b) normative force in general. By an 'epistemic schema,' I mean an hermeneutic filter that structures how one perceives and judges, which is to say, a cognitive filter that contributes to and in some cases directly confers meaning (Peña-Guzmán and Reynolds 2019). Epistemic schemas inform what and how one sees, what and how one thinks, and what one does and how one acts. By providing a foundation for reasoning, judgment, and belief about a range of phenomenon, principles create epistemic schemas; they create ready-to-use interpretive filters that allow one to quickly categorize, organize, and make intelligible a wide range of phenomenon. For example, Mill's greatest happiness principle - "actions are right in proportion as they tend to promote happiness, wrong as they tend to produce the reverse of happiness"-creates an epistemic schema or filter that can be used to interpret an extremely wide range of experiences in terms of cause-and-effect, namely, cause and effect with respect to the promotion or reduction of happiness.

Put simply, principles act as guides for experience. ${ }^{7}$ Principles are regulative cognitive tools. They conduct thinking and action with regard to as large a range of phenomena upon which they are taken to have purchase. It is in this sense that

\footnotetext{
${ }^{6}$ In Peña-Guzmán and Reynolds (2019), we argue that ableism is an epistemic schema. I here argue that ableism is a principle that generates epistemic schemas. We did not discuss the role of the principles in that piece due to the audience and other concerns at hand. I ultimately take these arguments to be compatible insofar as ableism functions as an epistemic schema precisely through its role as a principle.

${ }^{7}$ I am not making the argument that epistemic schemas necessarily arise due to a previous (logically or experientially) role as a principle. The larger relationship, causal or otherwise, between principles and epistemic schemas is beside the point here.
} 
principles can structure the meaningfulness of lived experience, sometimes with respect to a particular domain and other times with respect to one's lived experience as a whole. ${ }^{8}$ To return to Mill, the greatest happiness principle structures the classic Trolley problem thought experiment introduced by Phillipa Foot thought in such a way that its meaning is not a question of tragedy, caprice, theodicy, technological hubris, finitude, design, or any number of other things, but instead of the promotion of happiness. If one further takes the greatest happiness principle as the principle by which to live, then the meaningfulness of one's life as a whole can become fundamentally structured by it.

In addition, principles generate normative force. That is to say, they generate motivating reasons to care about phenomena in particular ways. They are in that manner binding in Brandom's sense of the term and regulative in Kant's sense of the term. That is to say, they guide and orient both thought and action toward certain ends and away from others (i.e., they are regulative), and these ends are assessed relative to the recognitive community or communities to which one is committed (i.e., they are binding) (Kant 1998; Brandom 2019). The normative force of principles contributes to the generation of that by which people come to care about the way the world is and ought to be such that they seek to maintain or change it.

Crucially, for a proposition or set of propositions to function as a principle does not require one to have reflected upon, expressed, or otherwise articulated those propositions or anything pertaining to their experiential role. Put simply, principles can operate implicitly or explicitly, and it is because of this that their articulation in propositional form is not necessary for their function to be carried out. That form merely makes explicit in a particularly helpful manner the ways in which a principle impacts one's or a community's thinking.

Among the ways that principles can function implicitly, there are a subset that are "stealthy," to borrow an apt term from Quassim Cassam that he uses to talk about virtue (Cassam 2018, 149). To understand some principles as stealthy merely touches the surface, however, for it is not just an issue of covertness, but also one of epistemic primacy and epistemic maintenance. As a wide swath of literature in social epistemology has argued, credences (degrees of belief in $\Phi$ given one's evidence) are shaped in part by one's interest in holding one's larger belief system in place (cf. Nguyen 2018). Whether or not I believe $\Phi$ or not $\Phi$ will in part depend on the extent to which the truth of $\Phi$ or not $\Phi$ call into question my larger system of beliefs about the world. People give epistemic primacy to credences central to their larger epistemic framework, and they work to maintain those credences as well as supporting ones, accordingly downgrading credences that present a threat.

If a given credence calls one's principles and larger epistemic schemas into question, then one will likely be predisposed to discredit the evidence for that credence.

\footnotetext{
${ }^{8}$ By construing principles in this manner and by further arguing that ableism is a principle, I am neither defending a generalist, nor a particularist position, nor a position somewhere in between. That is to say, I am neither making an argument concerning the defensibility of moral principles (or other sorts of principles) in general, nor making an argument about their proper role for moral thought or an ethical life. Cf. (Potrc et al. 2010).
} 
The greatest happiness principle enthusiast will likely place less belief in studies suggesting that happiness is profoundly subjective and variable since, whatever their merits, taking such studies seriously might fundamentally undermine that principle and its role in one's larger epistemic framework as a whole. This means that insofar as principles lead to multiple credences as well as centrally support larger epistemic frameworks central to one's larger worldview, any particular credence that in some way threatens a principle integral to that epistemic framework will have an especially uphill battle. As mentioned above, because principles can regulate in explicit or implicit ways, including ways that are conditioning, they can function without ever taking propositional or other sorts of discursive form. A more complete definition can now be offered: principles are regulative cognitive tools that determine the meaning and value of various domains of lived experience and which operate at varying levels of explicitness.

Now that I have defined a 'principle,' I can turn to the central topic of this paper: conditioning principles. A conditioning principle is a principle that implicitly or explicitly grounds, limits, or otherwise determines the possibility of other principles. That is to say, conditioning principles are determinative of which other principles a person holds as well as the role those principles play relative to one's larger epistemic framework. Furthermore, conditioning principles are especially liable to be stealthy in the sense described above. This makes them especially problematic both as objects of inquiry and as obstacles for epistemic transformation because conditioning principles are often actively hidden from one's reflective awareness, leading them to function as bulwarks of epistemic ignorance (as I discuss at length in Sect. 5.5 below). In the following section, I argue that ableism is a conditioning principle, and I focus on its ramifications in the field of bioethics, the practice of biomedicine, and philosophy more generally.

\subsection{The (Problem of the) Principle of Ableism}

Ableism can be defined in many ways, and there are ongoing debates in the humanities and social sciences over the best way to characterize the concept either in general or with respect to specific domains of inquiry (e.g., see Nario-Redmond 2019; Scuro 2017; Goodley 2014). My primary aim in this section is not to define ableism or demonstrate why it is problematic, but instead to show that ableism functions as a conditioning principle and, insofar as it plays this specific role, that it influences bioethical inquiry and argumentation in unreflective and critically undermining ways. It follows from my argument that any such conditioning principle deserves further interrogation.

Recall that in Sect. 5.2, I defined a principle as “(i) a proposition or set of propositions taken to be true for all phenomena to which it refers or otherwise generalizes over and (ii) which acts as the basis or foundation for further reasoning, judgment, belief, or related cognitive processes." I then defined a conditioning principle as a principle that implicitly or explicitly grounds, limits, or otherwise determines the 
construction and role of other principles, including which principles will appear intelligible and apt in the first place. Understood as a conditioning principle, ableism involves the conjunction of the following four claims:

1. Abilities or capacities are qualities, properties, characteristics, features, or dispositions of individuals.

2. Abilities create, comprise, and/or confer value upon the life of an individual.

3. Given (1) and (2), abilities are central to an individual's wellbeing, fundamental to the meaningfulness of their life, and determinative of their actual and also potential social standing, social roles, and social capital.

4. Disabilities, understood as a lack or deficiency of abilities as understood in (1), negatively impact one's value, per (2), and wellbeing, per (3). ${ }^{9}$

Recall that principles are regulative: they guide thinking in a way that allows a wide range of applications and that typically ends up being determinate for the meaning of the phenomena at hand. How then, do these propositions work together as a principle that grounds, limits, or otherwise determines and selects for other principles?

The principle of ableism leads people to determine the value of a given individual in terms of the abilities of their individual body and mind as well as in terms of the perceived achievements brought about or potentially brought about by each. Note that the principle of ableism does not deliver verdicts about which sorts of qualities, properties, characteristics, or dispositions of individuals should be considered abilities (as opposed to say, accidents or trivialities). ${ }^{10}$ That is to say, the conditioning principle of ableism does not provide a priori tools to know whether touching one's nose with one's tongue will count as an ability, disability, or as neither. Nor does the principle of ableism deliver verdicts about which sorts of abilities should or will confer value upon any given individual life. It instead guides people to think of abilities and disabilities in general in the ways detailed above, and it allows the content to be filled in.

It is for such reasons that ableism fundamentally involves idealization in the sense that instead of looking to actual phenomenon detailing the meaning of ability - whether with respect to questions of biology, sociology, history, anthropology, or philosophy, among other sources-the central abstraction it involves (viz., (1) above) is instead stipulated and, what's more, treated as common sense. Furthermore, the primary evaluative aspect of the conditioning principle-built into the

\footnotetext{
${ }^{9}$ This is obviously a case of what Elizabeth Barnes' terms a "bad-difference" view of disability (2016). Note that while I am arguing that ableism understood as a conditioning principle involves a bad-difference view of disability, it does not specify which abilities would be considered central to flourishing and which would not.

${ }^{10}$ It is important to note that the concept of ableism borrows part of its force from other perniciousisms (racism, sexism, cis-sexism, ageism, classism, etc.), but similarly to those terms, ableism is not merely or even primarily a question of individual beliefs or judgments It is instead a complex phenomenon with psychological, material, historical, and many other facets. I take my discussion of ableism as a conditioning principles to build upon such analyses.
} 
distinction between ability and disability, between (1) and (4) - is treated as obvious. If one were to operate with a nonideal understanding of the meaning of ability and disability, this evaluative aspect would appear absurd in this abstract form: one need only point to the countless cases of an 'ability,' as defined in (1), that in one culture and/or historical time period is considered to confer value upon a person and in another is considered to detract from or entirely negate their value.

Because it generalizes over the meaning and value of being human, it is hard to overstate the impact this conditioning principle has on questions of well-being and on larger, related socio-political questions. As a conditioning principle, ableism renders other principles-like beneficence, non-maleficence, and respect for autonomy - to be interpreted in ways that are predicated upon the existence and value of abilities so understood.

This leads one to downplay or ignore the fact that abilities and the values to which they are tied are fundamentally and necessarily relational and social (Reynolds 2018; Kafer 2016; Garland-Thomson 2020). From breathing to communicating to procreating to provisioning any of our basic or non-basic needs, there is nothing a human organism can do without a supporting environment; from sports to finance to feeling at home and from confidence to consumption to dance, there is no meaningful activity in which a human organism engages that does not require a supporting environment. The conditioning role of the principle of ableism obscures this fundamental insight. It misconstrues the nature of ability; it downplays or ignores the role of the social in determining the meaning of ability; and it supports an individualistic framing of wellbeing and social standing.

It thereby leads people to inflate the import of the individual, to misconstrue what Eva Kittay terms the "nested dependencies" without which we could not live, much less flourish, and to downgrade the actual role of systems of support, both social and environmental in kind. In short, the principle of ableism undermines the aims of justice as fairness by actively misrepresenting and misunderstanding the social, relational nature of human beings, human life, and human wellbeing as indexed by abilities and ability expectations.

This issue is not simply one of failing to appreciate the nature and complexity of abilities. It is also intimately related to a larger issue of understanding experiences unlike one's own. In her book Transformative experience, L.A. Paul argues that there are all sorts of experiences about which we are simply not in an epistemic position to comprehend: "stories, testimony, and theories aren't enough to teach you what it is like to have truly new types of experiences-you learn what it is like by actually having an experience of that type" $(2014,13) .{ }^{11}$ Examples of transformative experiences include being a parent, being an astronaut, undergoing a radical ability transition (becoming suddenly paralyzed from the neck down), religious transformation, etc. What's more, not only can one not know about certain types of novel, transformative experiences, a "radically new experience" can be "epistemically and personally transformative"-it can fundamentally change how one knows and who

\footnotetext{
${ }^{11}$ I am aware of the critiques of Laurie Paul from Agnes Callard, but I ultimately side with Paul.
} 
one is and will become (170). This argument does not simply apply to sets of experiences, however. It also applies to the meaning of any given individual ability relative to the larger context in which it is experienced as meaningful.

The relationship of a given discrete ability or set of abilities to wellbeing is not automatically or sufficiently determined by discretely comparing one's own abilities to the addition of another ability in question or to the lack of one currently has. This is so for the following two reasons. First, abilities are often transformative in the manner discussed above. Second, abilities are not properties, qualities, or features of one's individual body or mind, but instead of the interaction of one's body and mind with one's environment, social context, and networks, etc. (Reynolds 2018). As Eva Kittay puts it, "we have learned from disability community that disabilities are not in the body or mind of the disabled person. Although we commonly attribute a disability to a person, the disability is a consequence of an interaction between that particular person and the (social, physical, cultural, etc.) environment in which she finds herself. But if a feature of a person is disabling in a given environment, features of people are enabled in other environments. Thus, an ability, no less than a disability, is the result of the interaction of one's body and mind" (Kittay, personal correspondence; cf. Reynolds Forthcoming). That is to say, the meaningfulness of a given ability can only be understood in thoroughly contextual terms. The conditioning principle of ableism obscures this fundamental feature of human existence.

This is made clear by, among other sources, looking at evidence concerning perceptions of the quality of disabled life. There is a significant body of research showing that able-bodied people regularly underestimate the quality of life of people with disabilities (Basnett 2001; Bagenstos and Schlanger 2007; cf. Barnes 2016). This research suggests that, contrary to abled assumptions, people with disabilities in fact report similar levels of happiness with their lives as people without disabilities. But if ableism is functioning as a conditioning principle, this will seem absurd. To make that point painfully explicit, just consider how Albrecht and Devlieger frame such evidence (1999). They call it the disability paradox. It is only a paradox because they assume that the intuitions of able-bodied people must, surely, be right by holding that being disabled is bad for a person; the fact that many disabled people report being happy, surely, on this account, must be wrong in at least some way. With the conditioning principle of ableism underwriting one's thinking, to be disabled just is to be lacking or otherwise deviant with respect to one's abilities and thus invariably experience diminishment in one's value and well-being-that is what makes it a paradox that people with disabilities in fact report similar levels of happiness with their lives as people without disabilities. Without the conditioning principle of ableism, the paradox disappears and asserting it to even be a paradox would instead appear as an obvious and especially brazen case of hermeneutical injustice. I return to this point below.

To see ableism functioning as a conditioning principle in more detail, consider the following exchange between Eva Kittay, Peter Singer, and Jeff McMahan at a conference at Stony Brook University in 2008. This conversation presents-in a highly condensed, yet revealing manner-the heart of the debate between these 
three philosophers carried out across multiple years in academic journals and books (McMahan 2005; Kittay 2006; Singer 2009).

Peter Singer (directed at Eva Kittay): . . You've said a couple of times and you said it just again in response to the last question that you think that Jeff [McMahan] doesn't have the empirical stuff right... [with respect to] my comparison between humans and nonhuman animals...Well, can you tell us some of these morally significant psychological capacities in which you think that human beings, and let's talk about real ones, so the ones who are "profoundly mentally retarded," to use that term, in which they are superior to ... pigs or dogs or animals of that sort. (Eva Kittay responds by shaking her head.) It's a factual question. You can't just shake your head. You have to put up or stop saying that.

Eva Kittay: Peter ... you asked me how is Sesha [Eva Kittay's daughter] different from a — what did you say — a pig? And [when I shook my head] you said, well, it's a factual question, "put up or shut up." The first thing I have to do when you ask me that question, is I have to get over ... a feeling of nausea. It's not that I'm not able to answer it intellectually, it's that I can't even get to the point emotionally, where I can answer that question. (Pause.) Most of the time. When I say you can't just wave your hand and say "and so on," it's because there is so much to being human. There's the touch, there's the feel, there's the hug, there's the smile... there are so many ways of interacting. I don't think you need philosophy for this. You need a very good writer ... [T] his is why I just reject ... [the] ... idea that you [should] base moral standing on a list of cognitive capacities, or psychological capacities, or any kind of capacities. Because what it is to be human is not a bundle of capacities. It's a way that you are, a way you are in the world, a way you are with another. And I could adore my pig; I could dote on my pig. It would be something entirely different. And if you can't get that; if you can't understand that, then I'm not sure exactly what it is that you want to hear from me that I could tell you. ... I'll keep trying because I think this is a very important point (Kittay 2009, 621-22).

For philosophers or other academics who have been trained to ignore emotional, "gut" responses to various views, Eva Kittay's initial response comes off flatfooted. ${ }^{12}$ Yet, immediately after referencing her visceral reaction, Kittay clarifies exactly why she responds in such a manner: the very framework of Singer's question has, on Kittay's view, indefensibly narrowed the meaning of being human. Insofar as Kittay is right that Singer has done so through his focus on capacities, he is engaging in a textbook form of dehumanization. As David Livingstone Smith argues, "When we dehumanize others, we assign them a peculiar status. We typically think of them as beings that appear human and behave in human-like ways, but that are really subhuman on the inside" (Smith 2016; cf. Smith 2011).

Note that the idea that moral significance should be drawn along lines of species differences is but one particular form of the idea that moral significance should be drawn along lines of ability differences-about differences on the inside. Historically, if one heeds not simply evolutionary biology, but also sociology and cultural anthropology, what most distinguishes the meaning between species is not physiological form or function, but ability - ability as understood in its complex relationship to an organism's environment and social context (Fracchia and

\footnotetext{
${ }^{12}$ I have learned much from discussions with Lauren Guilmette on the exchange as well as her incisive and insightful analysis of this debate (Guilmette 2016).
} 
Lewontin 1999; Rieseberg et al. 2004). ${ }^{13}$ Individual "possession" of an "ability" does not determine worth except insofar as a given socio-cultural context confers worth on such an "ability" and, furthermore, conceives it as something an individual could "possess" in the first place. By denying the moral significance of species differentiation and arguing instead for moral significance to be decided in terms of ability or capacity, as Singer and McMahan argue, is to merely move the goal post within a long-established socio-political-philosophical lineage.

Herein lies the rub: if one is under the sway of ableism as a conditioning principle, it makes perfect sense to deny the species line as morally unfounded. With the conditioning principle of ableism in operation, the relevant factors turn on one's individual abilities, since, to repeat the claim of (3), abilities are central to an individual's wellbeing, fundamental to the meaningfulness of their life, and determinative of their actual and also potential social standing, social roles, and social capital. And, given (1), they are questions of the individual-not their interaction with an environment. And this is precisely why Singer and McMahan appear unable to comprehend Kittay's point. They do not hear her because ableism is functioning as a conditioning principle that determines how they understand the central terms of and moves within the debate.

To repeat the specific claims involved in the conditioning principle of ableism, recall that it involves the idea that abilities, insofar as they determine value, are definitive for the notion of moral status itself. That is to say, the conditioning principle of ableism, by definition, conditions the very meaning and import of other principles, such as those concerning moral status. Kittay's claim that "what it is to be human is not a bundle of capacities" only makes sense if ableism is not operative as a principle or as a conditioning principle in this way.

Understanding ableism as a conditioning principle helps explain why Singer and McMahan appear unable to grasp the reason why assuming claim (1) is philosophically — and, a fortiori, morally_problematic or, at minimum, up for philosophical debate. They simply take claim (1), as well as the other three claims, for granted, and insofar as they do, each claim works in the background of their thought, not needing proper defense or demanding meaningful scrutiny. At least with respect to

\footnotetext{
${ }^{13}$ It is important, I think, to realize that the idea that moral worth arises from capacities assumes that the complexity of certain organisms affords certain capacities that will make life go better. On its face, that idea flies in the face of contemporary evolutionary theory. "If the differential numerical representation of different types in a species occurs not by chance events of life and death, but because the properties of some organisms confer on them greater ability to survive and reproduce in the environment in which they find themselves, might there not be some properties that would confer a general advantage over most or all environments? Such properties, then, ought to increase across the broad sweep of organisms and over the long duration of evolutionary history, putting aside any particularities of history. So, for example, it has been claimed that complexity has increased during organic evolution, since complex organisms are supposed somehow to be able to survive better the vagaries of an uncertain world. Unfortunately no agreement can be reached on how to measure complexity independent of the explanatory work it is supposed to do. It is, in fact, characteristic of directionality theories that organisms are first arrayed along an axis from lower to higher and then a search is instituted for some property that can be argued to show a similar ordering" (Fracchia and Lewontin 1999, 62).
} 
this exchange and once one takes seriously the role played by conditioning principles, it is clear that neither Peter Singer nor Jeff McMahan understand the gravity of the fact that the principle of ableism conditions the foundation of their thought. Because of its conditioning role, it is further clear that they simply do not understand what Eva Kittay is in fact arguing.

For example, look at McMahan's reply, which entirely misses Kittay's point about the basic relationality of human beings and the way that human existence is a question of mode and not form:

Jeff McMahan: Let me say something on behalf of Peter's [Singer's] point of view here.... Peter has not said anything to deny the significance of a mother's relation to her own child. Nothing, as far as I can tell. The question here is a question about what moral demands there are on other people. And the fact that you, Eva, have a relation with your daughter doesn't necessarily give other people the same set of reasons that you have to respond to your daughter in certain ways and to treat your daughter in certain ways. The question is what it is about people like your daughter that makes moral demands on other people that nonhuman animals cannot make on any of us. That is the question that Peter is asking...

Eva Kittay: I know you're not trying to hurt anyone's feelings... [the issue is] what your writings might mean for public policy. That's what concerns me. And that's not just about my daughter.

McMahan thinks that the disagreement turns on denying the particularity of a mother's relation to her own child. This completely misses Kittay's point. Her point is primarily about the general meaning of being human, not the meaning of her particular relationship to her daughter. She is arguing against ableism; she is arguing against the idea that what it is to be human is a bundle of capacities. That idea is a terse encapsulation of the definition of ableism as a conditioning principle described above.

Although she references her experiences as a mother, those experiences are referenced by Kittay as an entry point to her concerns about the social and political implications of operating with the principle of ableism as one's default. If individual abilities are what ultimately create, comprise, and/or confer value upon the life of an individual, what will that belief imply for a society aimed at egalitarian ends? It will imply a society that lodges worth in what various beings can do. If the increasing horrors of climate change and the curtailment of the existence of nearly all species on earth are not enough reason to think that lodging worth in individual capacity is a problematic way to conceive of the ultimate stakes of moral obligation and deliberation, I'm not sure what would be. For thinkers such as Peter Singer, whose focus largely concerns the treatment of non-human animals as compared to human animals, perhaps the deepest and sadly ironic tragedy here is that this view could profoundly undermine the treatment and moral standing of any number of animals, human or otherwise.

Though I have offered some reasons why ableism is morally problematic as a principle, defending that view is not in fact my primary aim. I could hardly achieve that aim here given the countless defenses given in many different scholarly and political contexts by disability studies scholars and disability activists; there is simply not space to rehearse, much less do service to, those arguments (cf. 
Garland-Thomson 1996; Dolmage 2017; Nario-Redmond 2019). My primary aim has been to show that despite the fact that the principle of ableism lies at the heart of bioethical inquiry and biomedical practice, it has rarely been acknowledged as such. More specifically, it has rarely been acknowledged as a conditioning principle.

I analyzed the (in)famous exchange between Eva Kittay, Jeff McMahan, and Peter Singer as an example to explore how the principle of ableism in fact functions as a conditioning principle and to show how its function is problematic, regardless of which side one ultimately takes in that debate or in related others. Insofar as conditioning principles can have these sorts of effects and have them under the radar, as it were, this raises substantive concerns about the role of conditioning principles for any given theoretical domain in which they exert an influence, not least of which are the fields of bioethics and the practice of medicine.

\subsection{Ableism and Ideal Theory}

Conditioning principles do not merely arise out of nowhere-they arise out of the background beliefs, judgments, and interpretations through which our development as social creatures arises. But most philosophers pride themselves on working outside or at least in a critical relationship to such background phenomena. So why, as I have argued, would ableism have functioned for so long in so many domains related to disability? I find that one of the better explanations for this is due to the historical role of ideal theory in philosophical work concerning human nature and social relations.

Consider that to hold claim (1), one must be ignorant of research in phenomenology, ecological psychology, philosophy of disability, social ontology, and cognitive neuroscience to find the idea that abilities or capacities are properties of individuals not worthy of debate. Consider that one must be ignorant or insensitive to the profound moral implications of claim (2) with respect to research concerning human rights, peace and justice studies, and genocide studies. Consider that in order to hold claim (3), one must be ignorant of research in cultural anthropology, sociology (especially medical sociology), and, for that matter, history to think that ability values are not profoundly determined by a given historical and socio-cultural milieu. Finally, consider that one must be profoundly ignorant of disability history and disability studies to assume that having a disability eo ipso counts as a lack or that those disabled people who find it otherwise are mistaken about their own experience.

Claims (1)-(4) will, given the evidence referred to above, act as drivers for injustice. What's more, and as a significant number of scholars in social and political philosophy have argued, the principle of justice-bracketing whatever conditioning principles might underlie its understanding and application in any given case-is itself in important respects in tension with the realization of justice insofar as the principle of justice and the various theoretical apparatuses deployed to treat it are understood via the methods and terms of ideal theory (Simplican 2014; Mills 1997; Pateman 1988). 
Conditioning principles do the work of ideology: presenting contestable, questionable claims as premises or facts for thought and action. They undercut philosophical inquiry otherwise committed to various values by hiding themselves from critical view. In all these ways, conditioning principles should be a concern for everyone dedicated to critical reflection in the service of a more just world. As Charles Mills put this in his seminal article, "'Ideal theory' as ideology," "the ideal theory more dominant in mainstream ethics is in crucial respects obfuscatory, and can indeed be thought of as in part ideological, in the pejorative sense of a set of group ideas that reflect, and contribute to perpetuating, illicit group privilege" $(2005,166)$. Conditioning principles are by definition obfuscatory, and insofar as they support unjust, unequitable group privileges, they are unethical. This is why whatever it means to do nonideal theory in bioethics, it must include undoing the theoretical obfuscations that support the privileged and hurt the marginalized.

Understood in this light, when conditioning principles operate in ways that support extant privileges and maintain extant oppressions, conditioning principles can easily hide under the banner of "ideal theory" despite their role in hurting the marginalized. They can easily hide as things toward which we all, under veils of ignorance, would choose for a just society where we do not ahead of time know our place and station. But the very idea of "our place" in a society, however rouletted, is already shaped by the conditioning principle of ableism. Most take it as obvious that what one can do, the abilities or capacities one "has," will play a determinate role in one's wellbeing in any given society. As discussed above, this is so engrained that it sounds absurd to some. And yet, that assumption about individual ability evidences a profound ignorance about the meaning of ability and disability.

This is one of the problems with ideal theory: the conditioning principles that underwrite the decision-making of those under the veil of ignorance do not receive the scrutiny they deserve. Debates over ideal vs. nonideal theory often function as a proxy for a far more fundamental philosophical question: should philosophical analysis attend to people's lived experience and if so, in what ways? If one works in certain domains of logic or philosophy of physics, for example, this question might miss the mark and defensibly so. But it is necessarily on the mark in bioethics and socio-political philosophy, for these fields, in their many academically, clinically, and policy oriented variations, can wield a profound impact on a wide range of practices in the real world. The arguments I have proffered concerning conditioning principles is one way of arguing that without nonideal theory, these fields-and bioethics in particular-are doomed to reproduce the values and norms of privileged groups. What, then, would it mean to make decisions behind veils of ignorance that are not predicated upon conditioning principles such as ableism? Until we begin asking that question, the problem of ableism in particular and the problem of conditioning principles in general will go unresolved. 


\subsection{Ableism and Epistemologies of Ignorance}

One might at this point counter: humans are heuristic beings. We use a panoply of shortcuts in order to process and interpret the profound complexity of lived experience, much of which is implicit, vague, or otherwise ambiguous. Heuristics are not just defensible, but necessary. The idea of conditioning principles, the critic might continue, is thus a red herring to attack habits of thinking when the problem is not the form of the habit, but the content of the thinking. Principles of course create epistemic schemas that function as ready-to-use filters for one to quickly categorize, organize, and assign meaning to a wide range of phenomena: that is exactly what they should do. And, furthermore, humans need such cognitive heuristics to live and to survive. For such a critic, the argument of this paper is but a smokescreen. I think this objection is wrong for at least two reasons.

First, the issue of conditioning principles in bioethics and biomedical practice in particular does not turn on the prevalence of heuristics or prevalent biases such as confirmation bias or other psychological or existential propensities-whether ultimately explained by prosocial traits of evolutionary biology or widespread personal psychological habits developed to avoid discomfort, existential drives, or what have you. That is to say, the issue cannot be explained because humans are, point of fact, faulty thinkers. Whatever merit analyses of those sorts may have, the problem of conditioning principles I have outlined turns instead on the tension between the explicit normative goals of bioethical inquiry and biomedical practice and the discursive, reflective habits deployed by those in that domain. The concern with conditioning principles in these domains is ethical, not psychological. Insofar as conditioning principles exist and exist without morally defensible analysis and reflective concern, these habits run directly up against the normative goals of medicine as an institution devoted to care. The mere fact that humans offload, simplify, or act in bad faith with respect to ethical deliberations that run up against various cognitive habits is not a proper defense of such actions. As a rule, matters of fact don't presumptively settle normative concerns.

Also, there is a crucial difference at play here. Even if conditioning principles like that of ableism operate "in the background" like stock cognitive heuristics examined by researchers in psychology or cognitive neuroscience, they are distinct in a crucial way. Unlike many cognitive heuristics deployed by humans, principles are subject to voluntary control and re-education. If you think for instance about visual illusions, you can learn about an illusion all you want and try not to succumb to it, but you will always fall for it. When conditioned by certain factors resulting from typical human visual sensory perception, you will forever see certain lines as having different lengths when they are really the same length, to reference the Muller-Lyer illusion. Principles aren't like this_coming to understand a principle as wrong or a principle as correct can fundamentally and permanently change how one judges, perceives, etc.

Furthermore, not knowing that there are principles undergirding one's thinking and, further, failing to subject those principles to the same sort of critical analysis 
that one would subject other aspects of one (and other's) thinking is not simply a question of mistake or simple ignorance. It can be a question of epistemic justice. If one turns to research in social epistemology, the role of conditioning principles can often be seen as a question of what Gaile Polhaus Jr. calls willful hermeneutical ignorance and what Kristie Doston terms contributory injustice (Dotson 2012; Pohlhaus 2012).

That is to say, by failing to engage in active efforts to recognize and rectify conditioning principles, a person is in fact willfully choosing to remain ignorant. If I believe that all humans have equal value, but I also believe that people make certain choices that lead to their health, then I might blame an individual for their Type II diabetes or their chronic lower back pain. And I might do so despite the overwhelming evidence from social epistemology that it is not "personal choice," but social location that best predicts individual health outcomes; it is neither personal choice, nor even genomic code that best predicts health: it is one's zip code.

While this general concern holds across any number of cases, it is especially problematic ethically if one's social position involves privilege (Yancy 2006). Insofar as one's social position leads one to simply omit the hermeneutical resources of those who do not hold the particular privileges of one's own position, one commits willful contributory injustice (Dotson 2012). It is in this sense that conditioning principles can be drivers of epistemic injustice. How is that so? With respect to the analysis provided above, note that the level of explicitness of a given principle is in inverse proportion to its service toward epistemologies of ignorance. That is to say, the level of explicitness of a given principle is in inverse proportion to its service toward epistemic mechanisms that maintain the privileges of one's group and thereby contribute to the production of epistemologies of ignorance. More concretely, conditioning principles such as ableism are especially liable to generate epistemic injustice insofar as the claim that principle makes on an able-bodied person supports, and the way in which it maintains their participation in, the many privileges of able-bodiedness. In this light, conditioning principles can act as the lifeblood of hegemony, of unjust status quos.

I have argued that bioethics needs to take seriously the role of conditioning principles, that the principle of ableism is an especially problematic case, and that certain idealizing tendencies of philosophical theorizing are a reason why bioethics has failed at addressing the problem of ableism in particular and of conditioning principles in general. When we assess various bioethical principles and set upon a path to apply them, we do so not in an axiological vacuum but in a space that is already saturated with evaluations, judgments, and even principles, implicit or explicit. This normative plenum inevitably and profoundly conditions even our principled reflection in scope, content, method, and character, and we are responsible to take such things into consideration as part of moral inquiry. There is a way to avoid conditioning principles both in philosophy and in the field of biomedical ethics: we must become more critical about principles. We must engage in the work of genealogy, of critical intellectual history, and of the sort of humanistic inquiry that leaves no premise unturned. This is a high bar for thought, for practice, and for the infinite 
places at which they meet. But it is a needed metric to deliver on the promise of a more just, equitable, and liveable world.

Acknowledgments I am very grateful to the detailed and insightful feedback of the editors, David Peña-Guzmán, and Eva Feder Kittay.

\section{References}

Albrecht, Gary L., and Patrick J. Devlieger. 1999. The disability paradox: High quality of life against all odds. Social Science \& Medicine 48: 977-988.

Ariga, Samantha and Henry J. Heiman. 2018. Beyond health care: The role of social determinants in promoting health and health equity. Kaiser Family Foundation. http://www.kff. org/disparities-policy/issue-brief/beyond-health-care-the-role-of-social-determinants-inpromoting-health-and-health-equity/. Accessed 2 Dec 2019.

Arras, John D. 2001. A method in search of a purpose: The internal morality of medicine. Journal of Medicine and Philosophy 26 (6): 643-662.

Bagenstos, S., and M. Schlanger. 2007. Hedonic damages, hedonic adaptation, and disability. Vanderbilt Law Review 60 (3): 745-797.

Barnes, Elizabeth. 2016. The minority body: A theory of disability. Oxford: Oxford University Press.

Basnett, Ian. 2001. Health care professionals and their attitudes toward decisions affecting disabled people. In Handbook of disability studies, ed. Kathryn Seelman, Gary Albrecht, and Michael Bury, 450-467. Thousand Oaks: SAGE.

Beauchamp, Tom L., and James F. Childress. 2001. Principles of biomedical ethics. 5th ed. New York: Oxford University Press.

Ben-Moshe, Nir. 2017. The internal morality of medicine: A constructivist approach. Synthese 196: 4449-4467.

Brandom, R.B. 2019. A spirit of trust: A reading of Hegel's phenomenology. Cambridge: Harvard University Press.

Cassam, Q. 2018. Vices of the mind: From the intellectual to the political. Oxford: Oxford University Press.

Clouser, K.D., and B. Gert. 1990. A critique of principlism. Journal of Medicine and Philosophy 15 (2): 219-236.

Dolmage, Jay. 2017. Academic ableism. Michigan: Michigan University Press.

Dotson, Kristie. 2012. A cautionary tale. On limiting epistemic oppression. Frontiers: A Journal of Women Studies 33 (1): 24-47. https://doi.org/10.5250/fronjwomestud.33.1.0024.

Evans, John H. 2000. A sociological account of the growth of principlism. The Hastings Center Report 30 (5): 31-38. https://doi.org/10.2307/3527886.

- 2012. The history and future of bioethics: A sociological view. Oxford: Oxford University Press.

Fineman, Martha. 2004. The autonomy myth: A theory of dependency. New York: New Press.

Fracchia, Joseph, and R.C. Lewontin. 1999. Does culture evolve? History and Theory 38 (4): 52-78. https://doi.org/10.1111/0018-2656.00104.

Francis, Leslie. 2017. The significance of injustice for bioethics. Teaching Ethics 17 (1): 1-8.

Garland-Thomson, Rosemarie. 1996. Extraordinary bodies: Figuring physical disability in American culture and literature. New York: Columbia University Press.

2020. How we got to CRISPR: The dilemma of being human. Perspectives in Biology and Medicine 63 (1): 28-43. https://doi.org/10.1353/pbm.2020.0002.

Goodley, Dan. 2014. Dis/ability studies: Theorising disablism and ableism. London: Routledge.

Guilmette, Lauren. 2016. Curiosity-as-care: Feminist philosophies of disability, Foucault, and the ethics of curiosity. APA Newsletter on Philosophy and Medicine 18 (1): 46-50. 
Jonsen, A.R., S. Toulmin, and S.E. Toulmin. 1988. The abuse of casuistry: A history of moral reasoning. Berkeley: University of California Press.

Kafer, Alison. 2016. Feminist, queer crip. Bloomington: Indiana University Press.

Kant, Immanuel. 1998. Critique of pure reason. In The Cambridge edition of the works of Immanuel Kant. Trans. Paul Guyer and Allen W. Wood Cambridge/New York: Cambridge University Press.

Kittay, Eva Feder. 1999. Love's labor: Essays on women, equality, and dependency. New York: Routledge.

- 2006. At the margins of moral personhood. Ethics 116 (1): 100-131. https://doi. org/10.1007/s11673-008-9102-9.

-2009. The personal is philosophical is political: A philosopher and mother of a cognitively disabled person sends notes from the battlefield. Metaphilosophy 40 (3-4): 606-627. https:// doi.org/10.1111/j.1467-9973.2009.01600.x.

McMahan, J. 2005. Causing disabled people to exist and causing people to be disabled. Ethics 116 (1): 77-99.

Mills, Charles W. 1997. The racial contract. Ithaca: Cornell University Press.

Mills, Charles W. 2005. "Ideal theory" as ideology. Hypatia 20 (3): 165-184.

Morar, Nicolae, and Joshua August Skorburg. 2018. Bioethics and the hypothesis of extended health. Kennedy Institute of Ethics Journal 28 (3): 341-376.

Nario-Redmond, Michelle R. 2019. Ableism: The causes and consequences of disability prejudice. Hoboken: Wiley.

Nguyen, C. Thi. 2018. Echo chambers and epistemic bubbles. Episteme 3: 68-79.

Ouellette, Alicia. 2011. Bioethics and disability: Toward a disability conscious bioethics. New York: Cambridge University Press.

Pateman, Carole. 1988. The sexual contract. Stanford: Stanford University Press.

Paul, L.A. 2014. Transformative experience. Oxford: Oxford University Press.

Pena-Guzman, David, and Joel Michael Reynolds. 2019. The harm of ableism: Medical error and epistemic injustice. Kennedy Institute of Ethics Journal 29 (3): 205-242.

Pohlhaus, Gaile. 2012. Relational knowing and epistemic injustice: Toward a theory of willful hermeneutical ignorance. Hypatia 27 (4): 715-735.

Potrc, M., V. Strahovnik, and M. Lance. 2010. Challenging moral particularism. New York: Taylor \& Francis.

Reynolds, Joel Michael. 2018. The extended body: On aging, disability, and well-being. The Hastings Center Report 48 (S3): S31-S36, eds. Nancy Berlinger, Kate de Meideros, and Millie Solomon. https://doi.org/10.1002/hast.910.

—. Forthcoming. Worthy life: Disability, pain, and morality. Minneapolis: University of Minnesota Press.

Rieseberg, Loren H., Sheri A. Church, and Carrie L. Morjan. 2004. Integration of populations and differentiation of species. New Phytologist 161 (1): 59-69.

Scuro, Jennifer. 2017. Addressing ableism: Philosophical questions via disability studies. Lanham, MD: Rowman \& Littlefield.

Simplican, Stacy Clifford. 2014. The capacity contract: Locke, disability, and the political exclusion of 'idiots'. Politics, Groups, and Identities 2 (1): 1-14. https://doi.org/10.1080/2156550 3.2013.876918.

Singer, Peter. 2009. Speciesism and moral status. Metaphilosophy 40 (3-4): 567-581.

Smith, David Livingstone. 2011. Less than human: Why we demean, enslave, and exterminate others. New York: St. Martin's Press.

- 2016. Paradox of dehumanization. Social Theory and Practice 42 (2): 416-443.

Stramondo, Joseph A. 2014. Disabling bioethics: The case for a disability moral psychology and epistemology for bioethics for bringing my attention. Dissertation, Michigan State University. . 2016. Why bioethics needs a disability moral psychology. Hastings Center Report 46 (3): 22-30. https://doi.org/10.1002/hast.585. 
Symons, Xavier. 2019. Pellegrino, Macintyre, and the internal morality of clinical medicine. Theoretical Medicine and Bioethics 40 (3): 243-251.

Washington, Harriet A. 2008. Medical apartheid: The dark history of medical experimentation on black Americans from colonial times to the present. New York: Anchor Books.

Wilson, Duncan. 2013. What can history do for bioethics? Bioethics 27 (4): 215-223. https://doi. org/10.1111/j.1467-8519.2011.01933.x.

Yancy, George. 2006. Black bodies, white gazes: The continuing significance of race. Lanham, MD: Rowman \& Littlefield. 